\title{
A New Role for University Libraries
}

\author{
by Shirley Oakley, Executive Director, Library \\ Services, Charles Sturt University
}

$\mathrm{M}$

$\mathrm{y}$ topic today is the new role for libraries, and because I am a University Librarian, I will be talking about the new role for university Libraries.

I have spent almost 40 years in university libraries and over that time there have been many changes. Some of the roles I've filled don't exist any more and some of the roles that exist now didn't exist even 5 years ago.

In one sense the role of university libraries hasn't changed at all. What we do is support the mission of the University: its learning, teaching, research, and administrative functions. We always have, we always will.

What has changed is how we do that.

So what I'll do today is talk about

- The way we used to be

- The way we are now

- Why is it so?

- What does it mean for universities and their libraries?

- What happens in practice at Charles Sturt University library

- What happens next?

\section{The way we used to be}

Once upon a time, I'm sure most of us remember, university libraries were temples of scholarship and university librarians were the keepers of the temple.

We were serious places. We collected information resources which supported the scholarship of the university: the teaching and research activities of the academy. We had dense arrays of shelving packed mostly with print materials, some of which had not been used for years, if it had been used at all. We collected in advance of need so that we would have what was needed when it was needed - the "JustInCase" model.

Our catalogues provided access to what we owned. And what we owned was located in our buildings.

Our clients were called readers. They read stuff and we provided them with spaces to do that.

We provided individual study spaces for individual scholars and study halls for undergraduate students who were considered scholars-in-training. Some parts of the library and its collections might not be available to students.

People went were there to study. They worked alone, even though they might be quite densely packed together. The furniture was fixed and immoveable - you sat where we put you. No talking, no eating, no drinking, nothing like that. We employed special library stacks attendants who made sure nothing like that went on in our hallowed halls. 


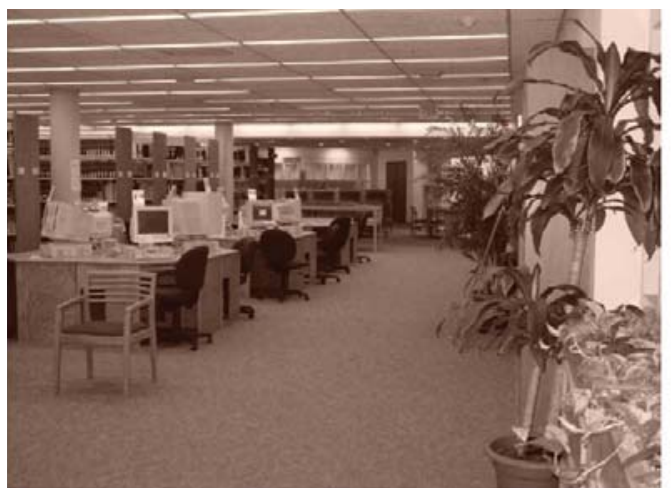

If you wanted something, you usually had to queue up to ask for it. Even when computers arrived it wasn't a lot different. Study was a single person activity and computers provided access to what we had chosen out of what was available in the scholarly communication world - the materials which (in our opinion) best supported our readers.

We had opening hours. Other times we were closed and our resources were largely unavailable.

We measured our worth by the size of our collections and the size of our budgets; and the number of loans we made and the number of entries into our buildings.
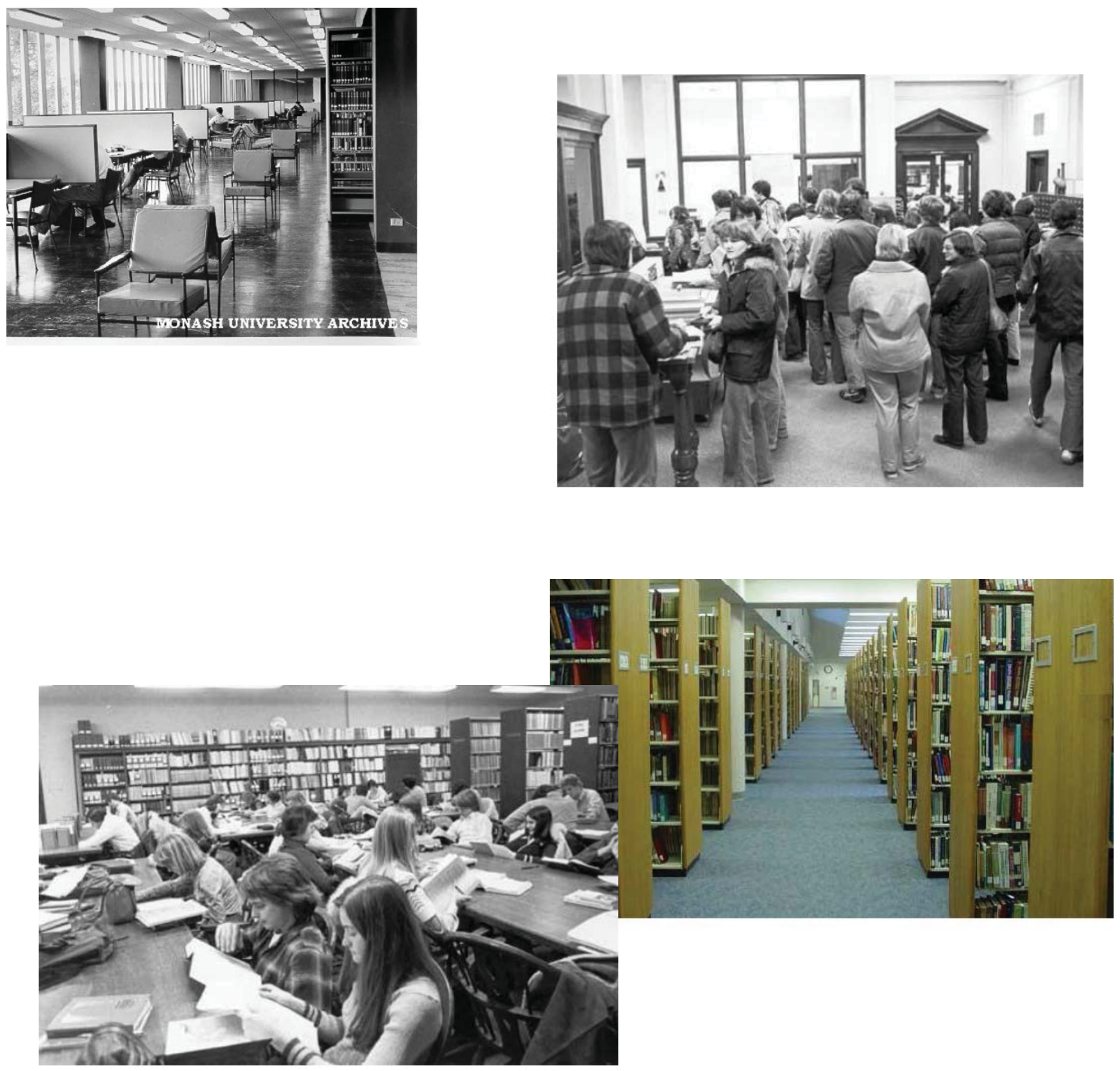

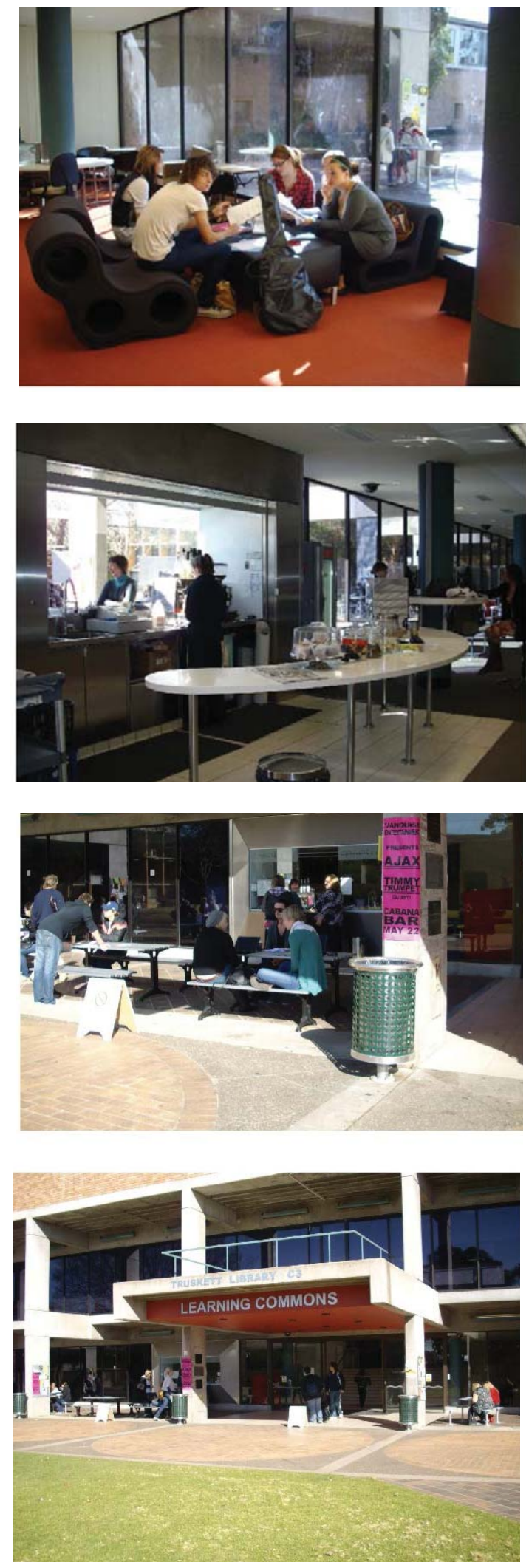

\section{The way things are today}

Now things are very different. We usually don't even call our buildings "libraries" - they are information commons or learning commons. We have clients rather than readers. Scholars don't come to the library - they access remotely. Our primary inbuilding users are students.

Students don't come to the library to read stuff - they come for other things. There's deep suspicion among many academics that students don't read anything anymore anyway.

They work in groups. They talk. They use their mobile phones they consider this a fundamental human right.

They move the furniture around to suit their immediate needs. They certainly don't sit the way we think they will. If all else fails they sit on the floor.

They bring their own technologies, so we need power points as much as we need fixed computers - maybe more than we need fixed computers. Increasingly the technologies they bring are handheld devices rather than computers.

Far from banning eating and drinking, we provide cafes during opening hours and vending machines for after hours' refreshments.

Outside is just as important to the students as inside. We need wireless access everywhere, and we lend laptops.

Access to technologies is important but only as a tool. If it isn't online it isn't real, they don't want to know - they don't trust that kind of information resource.

When we aren't open, students have access to all of our services and there is 24 hour access to at least part of the space and the technologies in the space.

Students even sleep in there.

Our collections are largely electronic - they can be accessed from anywhere, any time. We don't own the resources any more, we provide access to them. Mostly they are actually located offshore.

We now measure our worth by the number of hits on our electronic resources and our online services; by the number of enquires we get and how successful we are at answering them; and through surveys of client satisfaction which measure delivery against expectation.

\section{Why is it so?}

Things have changed. The world had changed. Higher education has changed. Students have changed. The way they are taught has changed. The way they learn has changed.

Let's start with changes in higher education - some of them anyway. This is a surface skim rather than an indepth study.

I'm going to concentrate on the changes affecting students because this has the biggest impact on the new roles for university libraries. The way we support research and administration in universities hasn't really changed in its fundamentals - the delivery mechanisms have changed - they don't come to us, we go to them. However the 

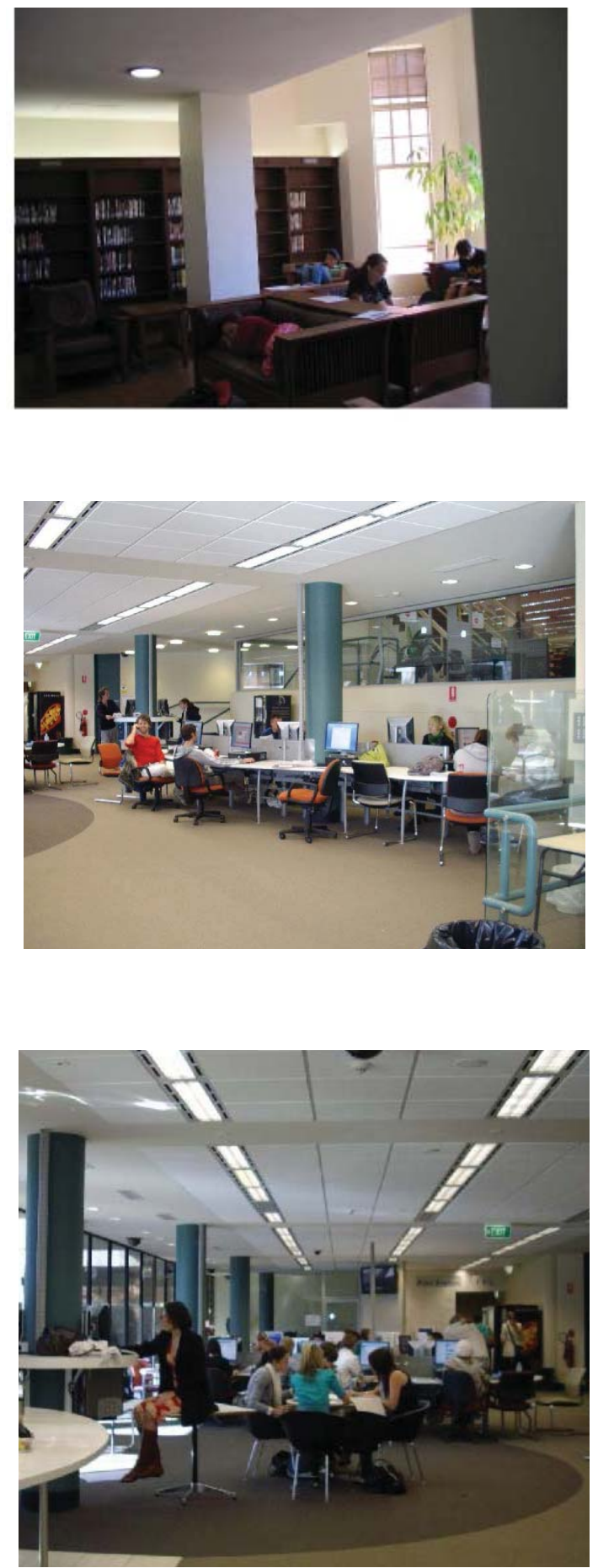

way we support students had changed significantly and it isn't all down to technology.

\section{Changes in higher education}

We've had what's often referred to as "massification"- the numbers of students in higher education has increased. They experience large class sizes or high student/teacher ratios. They feel that noone knows them as individuals.

There is a wide range of student cohorts: not predominantly school leavers any more. There are larger numbers of mature aged students; professionals returning to education to upgrade their employment skills or change career.

There are increasing numbers of offcampus students studying in various kinds of distance modes.

There's a view that higher education has been commoditised: as students pay more and more of the cost of their education, their expectations change. They have a consumer view of what they are provided with and expectations to match.

They are juggling multiple responsibilities so they are time poor and not on campus much. If they are enrolled in distance mode, they are not on campus at all.

There is increased competition between universities for student numbers.

Government funding is an increasingly lower percentage of total revenue: fee paying activities are increasingly important and the higher the fee, the greater the expectations of the students.

Internationalisation is important, not only in the content of the curriculum - we are training people for the global economy - but also in terms of fee paying student revenues.

International students are important both onshore on our main campuses and offshore in satellite campuses.

\section{Changes in students}

I already touched on changes in the student cohort in higher education. There are a wide range of students entering higher education in a wide range of study modes.

There are differences in the learning styles of the different groups of students. You've heard about 21st Century Learners already today, but of course not all students fall into this cohort. Mature ages students and professionals upgrading or extending their qualifications are also part of the mix.

And even the technologically-savvy student cohorts are not technologically-savvy in the academic learning environment something that surprises them as much as it surprises their teachers and the service providers that support them.

\section{Changes in the way students are taught}

There has been a fundamental shift in universities from a focus on teaching to a focus on learning. 


\section{"Service delivery} is a fundamental part of the student experience and university libraries are service providers. We must address the quality of the student experience as well as contributing to increased participation and overall success at university."
Group work and problem based learning are common across multiple disciplines. The teacher is a facilitator in the learning process. Students tackle openended problems, defining their own learning needs and the resources they required to tackle those problems.

Flexible delivery of coursework imposes multiple pathways for learning: there is no certainty that on-campus students are undertaking the lecture / tutorial model that was the norm not so long ago.

\section{Changes to come}

Under current federal government policy there are fundamental changes to come.

Funding will follow the students. There will be no quotas on enrolments any more - you may have as many students as you like in courses - and if you don't provide marketable courses you might not have any students at all.

Government policy is also focussed on extending participation particularly into low SES groups and for Indigenous students. This means universities face a wide variety of entry pathways into their courses and some students will be less "university ready" than students are now. It may be that students enter university for example via TAFE articulation pathways - in the second year of their course, not the first year. This has implications for ensuring all students have fundamental skills in their discipline and in their ability as autonomous adult learners.

Funding will be based on a "compact" between the university and the Commonwealth - in line with the agreed mission of the particular university.

There will be an emphasis on standards and quality assurance you may be able to enrol as many students as you like, but there will be measures in place to ensure they have reasonable chances of success - not just funding fodder. Accountability requirements will be a very high priority.

\section{What does this mean for universities?}

In some ways we wish we knew. However, like death and taxes, some things are reasonably certain. There will be increased competition for student numbers. There will be a high focus on the student experience as a distinguishing feature of different universities and a recruitment strategy. At CSU for example, we define the student experience in terms of increased potential for participation in higher education and successful outcomes from that participation. We know there are intangibles too: you can participate and graduate successfully and still have a poor university experience.

\section{What does this mean for university libraries?}

Service delivery is a fundamental part of the student experience and university libraries are service providers. We must address the quality of the student experience as well as contributing to increased 


\section{"Our principal role} is still to support and develop information

literacy skills in students but we will increasingly be targeting a wider range of university 'readiness"' participation and overall success at university.

Our principal role is still to support and develop information literacy skills in students but we will increasingly be targeting a wider range of university "readiness" - students will be operating at different levels of understanding of the academic process and how to engage with it successfully.

We need to support the changes in teaching and learning styles and flexible delivery.

We need to develop new service delivery models to cater for flexible delivery modes, increasing reliance on technology, time poor students, and students who are rarely, if ever, on campus.

\section{In practice}

These changes affect everything from building design through service design to service delivery.

Let's consider what CSU Library is doing - which is by no means unique in university libraries. However, since $75 \%$ of our 33,000 students are off campus in one mode or another, we have some unique challenges.

\section{Building design}

We have just completed a brand new library building at our Thurgoona campus. In the design process we looked at the pedagogies that the building would support. A range of pedagogies will occur across the whole learning $\&$ teaching precinct at Thurgoona including in the student bar!

\section{PEDAGOGY SPACE MAP - LEARNING \& TEACHING PRECINCT}

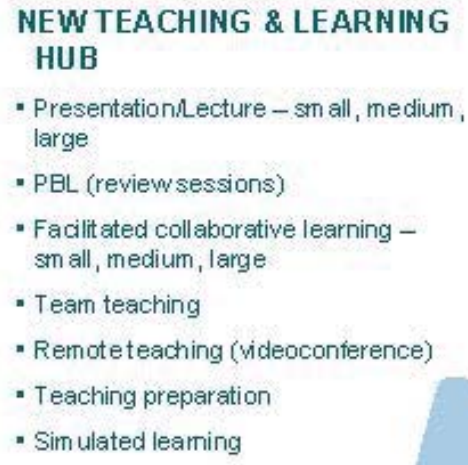

- Presentation/Lecture - sn all, medium, large

- PEL (review sessions)

- Facilit ated collaborative learning sn all, medium, lange

- Tearn teaching

- Remoteteaching (videoconference)

- Teaching preparation

- Sim ulated leaming

\section{LECTURE THEATRES}

- Presentationilecture - sn all, medium, large

- Remoteteaching

- Facilit ated collaborative learning

- small
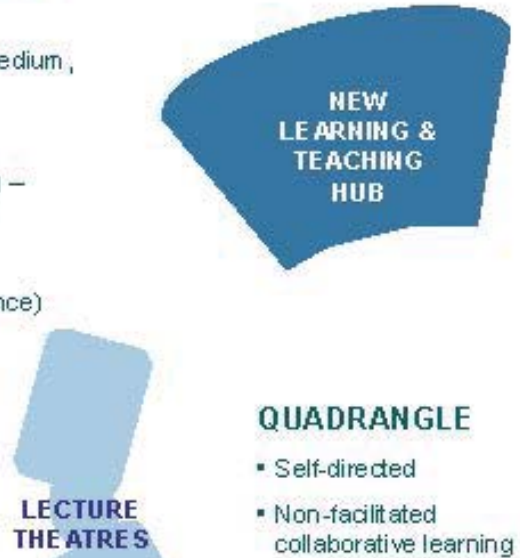

\section{QUADRANGLE}

- Self-direded

- Non-facilit ated collaborative learning
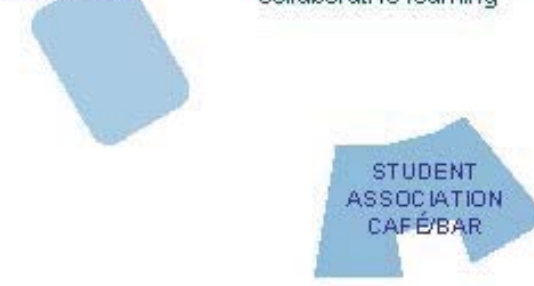

HEW

LEARHIIG

COMHOHS

NEW LEARNING COMHIONS

- Self-directed

- Non-facilitated collaborative learning

- Sim ulated leaming

- Facilitated learning

- Presentation/Lecture - small

- Remoteteaching

(Videoconterenoe) 
You will note that we are a learning commons. The learning commons will support

- Selfdirected learning

- Nonfacilitated collaborative learning

- Simulated learning

- Facilitated learning

- Small presentation/Lectures, and

- Remote teaching (Videoconference)

We mapped the learning strategies involved in the pedagogies identified as relevant to the building and the zones in which the various activities would take place.

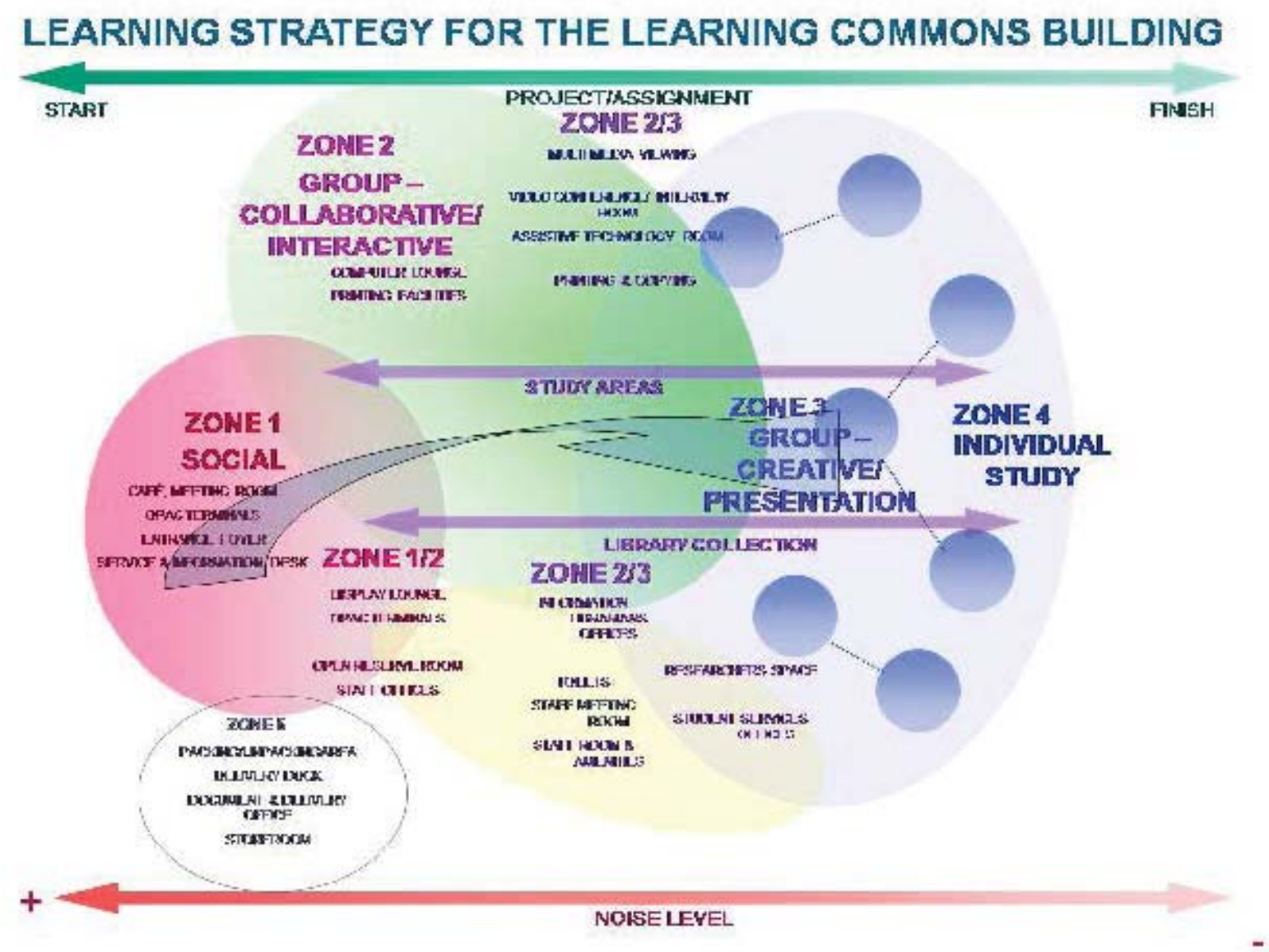

These zones move from highly interactive, noisy social spaces through group collaborative and group creative spaces to individual study spaces. As collaboration decreases, the noise level decreases. The idea is to design the spaces, colours, fixtures and fittings to indicate to users what sort of space they are in. The 24 hour access zones are located in the red and green zones.

Next we indicated the special relationships and space requirements for each of the identified functional zones as a guide to the architect. This is not a floor plan or a building design; it is a spatial relationship map. 
Quite a lot of the building is devoted to functions not traditionally considered to be library functions. Some of the services are not delivered by the library, but the staff delivering those services are located in the building.

The Thurgoona Learning Commons opened in February this year and was an instant hit with students and academic staff as well.

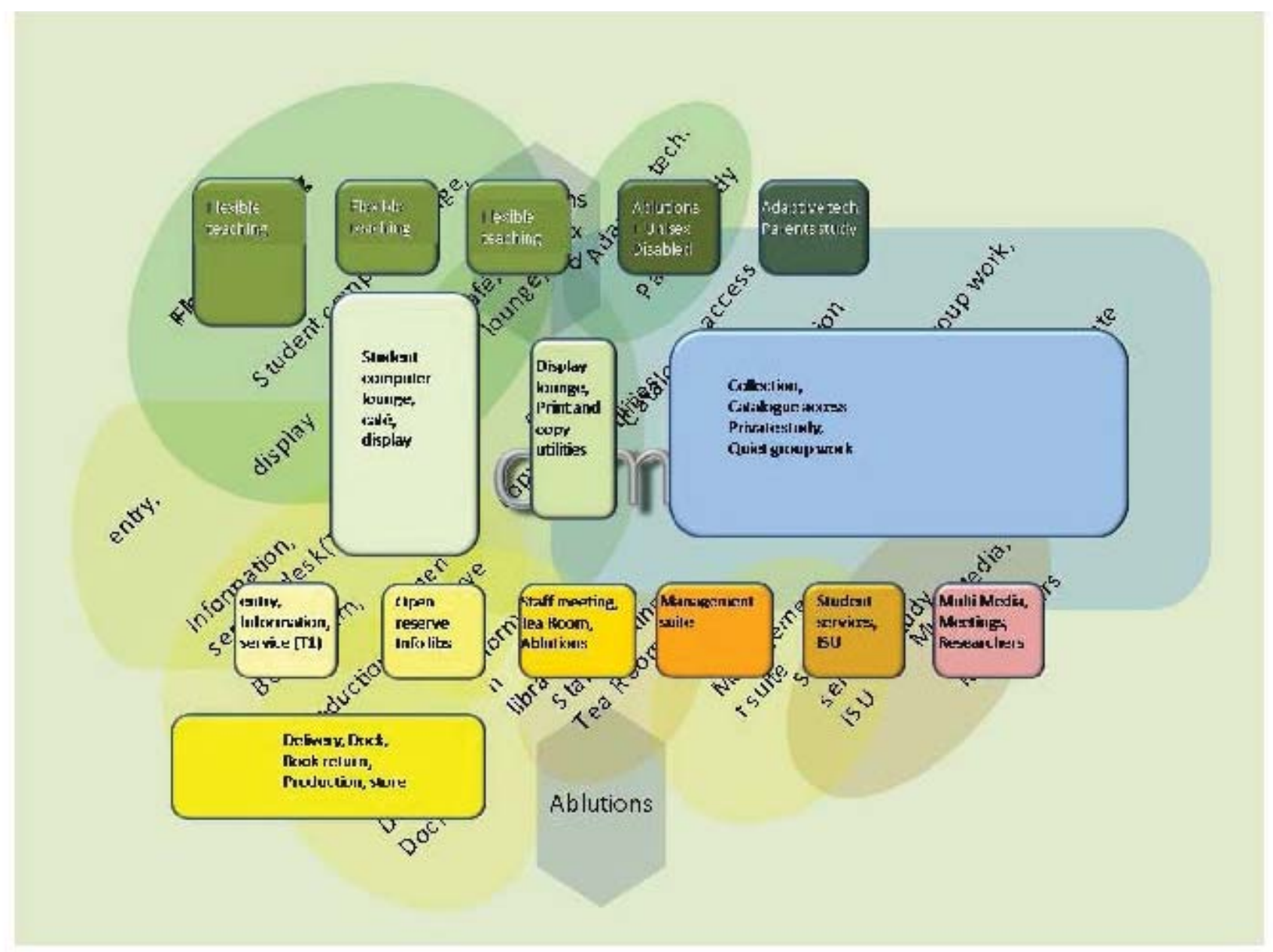

\section{Service design}

In designing the services to provide a high quality, supportive environment which enhances the student experience, we have to consider the service continuum. Students need a range of service support in their day-to-day engagement with the university and basically they don't care who provides what - they just want to know what they want to know.

However, organisationally these services are provided by a range of different organisational units which traditionally operate in silos. It is increasingly difficult in our complex environments to distinguish where one sort of support ends and another begins. Student queries most frequently morph from one to the other. Every staff member offering student facing services, including those in the Faculties, must be prepared to be multifunctional. Silos are dead. But they are 
hard to kill. I don't claim we have done it at CSU, but we are moving to solve the problem.

It's easier to be silo free at say the learning support end of the

\section{Student support continuum}

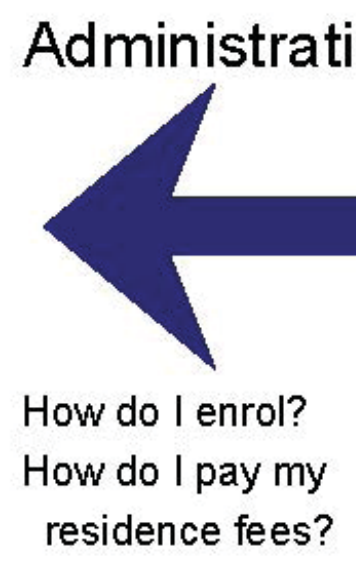

How do I print?

How can I contact

my lecturer?

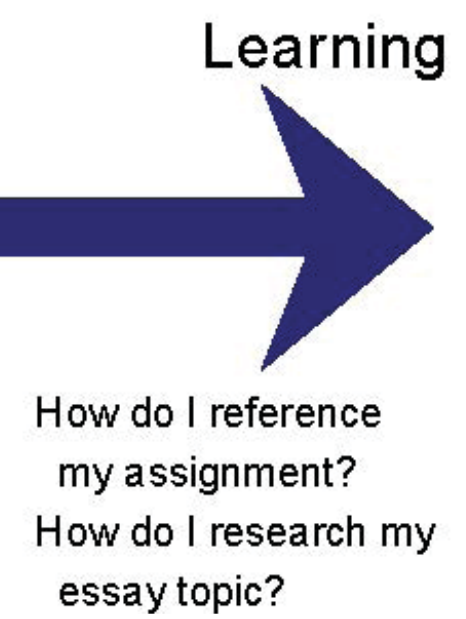

continuum, but much harder to blend service support across the whole range.

\section{Service delivery - the how}

In designing service delivery we need to consider

- The student perspective - what would I want if I was a student?

- What levels of service can we realistically expect to deliver using multifunctional staff and what requires greater expertise?

- What delivery methods will meet the needs of students? who are don't forget, time poor, at varying stages of "university readiness", predominantly off campus, and expect instant gratification.

We defined tiers of service.

Tier zero is self help - resources available in anticipation of need at point of need at time of need. We want as many enquiries as possible answered at this level. In libraryspeak these are things like when are you open? How do I recall a book? Where are the 600s? How do I use the catalogue?

Tier one is first line, generic support - traditional front desk stuff. We want to analyse these queries and develop Tier zero resources to support them.

Tier 2 is where specialist help is required - these will always be escalated to content experts, as seamlessly as possible. Reference librarians provide these sorts of services - you need help for a specific and relatively unique problem. 
Tier 3 is in depth or crisis help - the expert reference interview; assistance for researchers; that sort of thing. In the crisis area, Student Services assistance for things like students in crisis or in danger of exclusion from their course.

\title{
Service support levels
}

\author{
Tier 3 - In
}

depth - critical

incidents

\section{Tier 2 - Specialist}

\section{Tier 1 - First line - generic}

\section{Tier 0 - Self help}

\section{Delivery methods}

We are, like nearly everyone else, engaged in the Web 2.0 world, trying to out-Google Google. So we do all these sorts of things:

- Chat, Forums, Email, Phone, Twitter

- Podcast and vodcast

- Integration in online subject resources

- Have a look at our website to get a flavour of the sorts of things we do.

Frequently we provide these service delivery channels ahead of IT provision within the University and using freely available services on the Web. We need to move faster than the slow pace of infrastructure change within the university's own systems.

We know the students want these services because they tell us they do in our various feedback channels. They are quite vocal about it. We know they use these services from the statistics we analyse.

\section{Challenges}

There are a number of challenges, not least of which is money - we are not funded to be cutting edge - maybe leading edge but definitely not bleeding edge.

- How do you keep up with where the students are (in their various cohorts)?

- How do you know if this is a valuable tool or a passing fad? 


\section{"How do you}

maintain staff self-

worth? There is a

serious challenge

to be faced by

professional staff

who used to gain

their professional

identity from

helping people

face-to-face or

through the virtual

equivalent of face-

to-face. Now we

are asking them

to measure their

worth in how

few face-to-face

questions are

asked."
Should you care? Should you just use it and then leave it when it passes away?

- How do you keep staff skills up-to-date? These are things we were never trained to do - most library studies graduates still aren't.

- How do you maintain staff selfworth? There is a serious challenge to be faced by professional staff who used to gain their professional identity from helping people face-to-face or through the virtual equivalent of face-to-face. Now we are asking them to measure their worth in how few face-to-face questions are asked. We want Tier Zero to dominate. Staff may be very willing to engage, but this redefinition of professional worth is still a struggle for many.

- How do you do it fast enough and still maintain the required rigour in evaluating cost effectiveness and sustainability? All of the service delivery modes we have added have added transactions - there has not been any corresponding decrease in other delivery modes. Are we reaching new cohorts? Or are we providing new channels for the same cohorts?

And finally:

- How do you avoid the "Creepy Treehouse" effect?

In the field of educational technology a creepy treehouse is an institutionally controlled technology/tool that emulates or mimics preexisting technologies or tools that may already be in use by the learners, or by learners' peer groups. Though such systems may be seen as innovative or problemsolving to the institution, they may repulse some users who see them as infringement on the sanctity of their peer groups, or as having the potential for institutional violations of their privacy, liberty, ownership, or creativity.

ht t p: // f lexknow logy. learningf ield. org/ 2008/ 04/ 09/ def inin gcreepyt reehouse/ Accessed 5 July 2009

Are we inserting ourselves into student spaces which they consider off limits for the purposes we use them for?

\section{Still to come}

Still to come for CSU Library are the problems I touched on in relation to the Thurgoona Learning Commons building. We now need to provide services beyond our more traditional focus on learning support. These services are designed and maintained by other organisational areas of the University. We know that we are truly great at answering all sorts of student questions, but we also know in our deepest gut that only we can answer library related questions. Our colleagues feel exactly the same. The students don't distinguish - they just want accurate information. We already have service providers from other Divisions in our Thurgoona building. Other buildings will follow the same pathway.

The fundamental questions then are:

- Whose building is it? 
- Who decides who can come into which bits when?

- What management models will we use to sort these things out? 